Western University Scholarship@Western

1976

\title{
Added- and Discouraged-Worker Effects in Canada, 1953-1974
}

Peter J. Kuch

Shmuel Sharir

Follow this and additional works at: https://ir.lib.uwo.ca/economicsresrpt

Part of the Economics Commons

Citation of this paper:

Kuch, Peter J., Shmuel Sharir. "Added- and Discouraged-Worker Effects in Canada, 1953-1974." Department of Economics Research Reports, 7605. London, ON: Department of Economics, University of Western Ontario (1976). 


\section{RESEARCH REPORT 7605 \\ ADDED - AND DISCOURAGED-WORKER EFFECTS \\ IN CANADA, 1953-1974*}

by

P. J. Kuch and S. Sharir

February, 1976

*W. Haessel, R. Carter and D. Scheffman provided valuable suggestions and helpful comments on an earlier draft of this paper. Any remaining errors are the sole responsibility of the authors. 


\section{ABSTRACT}

This study uses monthly labour force survey data to isolate the discouraged-and added-worker effects in the participation behavior of ten sex-age groups of the Canadian population. It compares the magnitudes of each of these effects across groups and estimates the net cyclical response that prevailed during the period 1953-74. Finally it explores the possibility of non-symmetries in these effects with respect to improving and deteriorating labour market conditions. 


\section{Introduction}

To the extent that the size of the labour force varies in response to cyclical changes in labour market conditions the official unemployment statistics-while relevant for the estimation of the excess supply of workers in a given market situation (Mincer, 1966, 101-2), will not be appropriate, and will require revisions for other purposes. Among such purposes are the estimation of the social cost of induced recession, the potential for economic growth, the number of jobs government policies must generate to cure mass unemployment and the understanding of certain forms of social unrest. With this in mind, economists have been trying to determine how the labour force reacts to cyclical changes in the demand for labour services and what forces produce these reactions. This paper is an attempt to increase our understanding of these issues.

Two opposing hypotheses, the "discouraged-worker effect" and the "added-worker effect", have been advanced to describe the effect of the business cycle on labour force participation. Today there seems to be general agreement that both effects are likely to operate simultaneously. Dernburg and Strand (1964 and 1966) succeeded in isolating these two effects for the U.S. However, Mincer $(1966,81-4)$ has challenged their results in the 1964 paper on various grounds. Of particular interest to us here, is his claim that the magnitude of their added-worker effect cannot be correct, since it implies that if one family member exhausts his unemployment compensation benefits, 12 family members will enter the labour market. A similar criticism, though to a lesser degree, could be made of their results in the

1966 paper. $^{1}$ Moreover, in their 1966 paper the group labour force participation 
rate is defined in an unusual way (the ratio of the group's labour force to the total population) without adequate explanation. A subsequent attempt by Barth (1968) was not successful in finding two distinct effects. All of the other studies to date have side-stepped this issue and essentially been concerned with estimating the net effect of these two phenomena.

The U.S. studies, both those using cross-section data--Cain (1966, $62-6,152-4)$ and Bowen and Finegan (1969, ch. 15), and those using timeseries data--Tella (1964, 1965) and Bowen and Finegan (1969, chs. 16 and 17) found a net discouraged-worker effect for almost all the population subgroups. No such uniformity is found in Canadian studies. The tine-series studies--Proulx (1969), Officer and Anderson (1969), Davis (1972), Swidinsky (1973), and Swan (1974)--obtain contradictory results with respect to several population subgroups. Nevertheless, there appears to be a general tendency toward a net added-worker effect in these studies. However, a cross-sectional study using Canadian data by Swidinsky (1970, 1973) finds a net discouraged-worker effect for all population subgroups. It is no surprise then, that there is some uneasiness, e.g., Swan (1974, 431), concerning these confusing results.

This paper attempts to contribute to the literature in several ways. First it suggests a new and straightforward technique for separating the discouraged- and added-worker effects. Second, it provides estimates of the magnitude of each effect for various sex-age groups in Canada, and utilizes the concepts of primary and secondary labour forces to explain these results. Third, while it falls short of providing a theoretical explanation for the so far confusing results found for Canada, it seems to go a long way toward clarifying the issues involved. Fourth, using the framework developed 
in the paper, it provides estimates of net cyclical effects for the various sex-age groups. Finally, it raises the issue of symmetry in the two effects with respect to deteriorating and improving labour market conditions, discusses possible reasons for asymmetry and reports results concerning this issue for Canada.

\section{The Theoretical Considerations}

During the last decade, the discouraged-and added-worker effects have been formalized within a general model of family utility maximization (e.g., Cain (1966, 62-6), Mincer (1966, 76-7), and Bowen and Finegan (1969, 21-22)). As it is usually defined the "discouraged-worker effect" is an own-substitution effect. Deteriorating labour market conditions (declining labour demand) will tend to reduce the probability that a person without a job. will find one and/or reduce the real wage rate received by those who have jobs. This in turn reduces the expected reward from spending one's" time in the labour market relative to the expected reward from non-market activities, producing a substitution against market participation. This phenomenon relates to people already in the labour market, presumably the unemployed, who become "discouraged" and leave the market, as well as to people outside of the market who intended to enter, but who are "discouraged" by the experiences of others and as a result delay their entry. Both sorts of behavior will tend to reduce labour force participation. ${ }^{2}$

The "added-worker effect" is usually conceived of as a combined cross-substitution and a real family income effect. The loss of jobs and subsequent failure to find new ones by some family members (and/or. 
the decline in their real wages) caused by deterforating labour market conditions will tend to "send" other family members into the labour force or induce them to stay in the labour force longer than they had planned to. This may happen if their expected rewards from participation in the labour market have increased relative to those of family members who can no longer secure a job (or whose real wages have declined). It may also happen, if the non-market activities (e.g., leisure) of family members are normal with respect to real family income. The reduction in the real earnings of family members who participated in the labour market will then tend to propel those who were not already participating into the market. Both effects reinforce each other, increasing labour force participation.

Although, as in the preceding discussion, the discouraged-and added-worker phenomena are usually explained in terms of deteriorating labour market conditions, it is expected that the converse reasoning would also hold, so that when labour market conditions improve the labour force flows can be assumed to reverse themselves.

\section{The Statistical Model and Hypotheses}

It is obvious from these theoretical considerations that the discouraged-worker effect refers to labour market conditions (changes in demand, given supply) which are specific to the individual or the relevant group of individuals. Whereas, the added-worker effect refers to labour market conditions (changes in demand, given supply) facing other members of the family or other groups of individuals. We therefore suggest a separation of these two effects for any group of individuals by using an 
index of their specific labour market conditions and an index of the labour market conditions for all other groups.

The most frequent measures of labour market conditions used in studies to date have been the unemployment rate and the employment to population ratio. We prefer the latter measure because the unemployment rate itself is affected by the degree of labour force responsiveness to labour market conditions, the very phenomenon we are trying to estimate, and is thus hardly an independent variable. Furthermore, changes in the employment to population ratio are directly related to the changes in the level of labour demand, which are hypothesized to produce the cyclical changes in labour force participation. ${ }^{3}$

The preceding discussion suggests that we consider the relationship between a particular group!s participation rate, PR, its employment to population ratio, ER, and the ratio of the total employment of all other groups to the total population of those groups, OER. Furthermore, since we are concerned exclusively with the effect of the business cycle and are using time-series data, a time trend variable, $T$, is employed to capture secular (longer than cyclical) changes in, the groups' participation behavior. (In order to remove shorter-run, seasonal, variations in the participation rate we shall use seasonally adjusted data.) The general model suggested by these arguments is

$$
P R=f(E R, O E R, T)
$$

The theoretical considerations in section 2 do not suggest a particular specification for relationship (1). We agree, however, with Proulx (1969, 274) that the effect of the trend variable on the participation rate is likely to be non-1inear. But otherwise, we prefer to use the simplest possible functional 
form for (1). Thus, we have estimated the following equation: ${ }^{4}$

$$
\mathrm{PR}_{t}=a+b E R_{t}+c \mathrm{OER}_{t}+d T+e \mathrm{~T}^{2}+\epsilon
$$

where PR, ER and OER are as defined above, $T$ is a time variable which takes on consecutive values, $0,1,2$, etc., $t$ denotes the $t$-th period and 6 is a random error term. It should be noted that the linearity with respect to ER and OER makes equation (2) comparable to the linear equations estimated in all the other literature on this subject. However, in order to determine how sensitive our results are to the particular functional form chosen, we have estimated a double-log formulation in $P R$, ER (but semi-log in $T$ ), and number of different time trend specifications. We shall discuss the main results of these alternative specifications in Section 6.3 .

Since both ER and OER are directly related to the relevant labour market conditions they are supposed to measure, our a priori expectations are that we shall find $b>0$ and $c<0$. The former represents the discouraged-worker effect, while the latter represents the added-worker effect. We have no a priori expectations concerning the signs of ' $d$ ' and ' $e$ '.

As concerns the relative magnitudes of these effects across the various population groups, as measured by the partial elasticities derived from the coefficients, we expect both the effects to be smallest for groups comprising the "primary labour force." The primary labour force is conventionally defined as consisting of people who are firmly wedded to the labour market, as distinguished from the "secondary labour force" which is composed of people who have only a weak (or casual) attachment to the labour market. The degree of a population group's labour market attachment can be measured by its mean labour force participation rate. In this context, the participation rate is interpreted as indicating the proportion of time individual members of the group spend on average 
in the labour market. ${ }^{5}$ On the basis of this interpretation the primary labour force is usually defined as consisting of males in their prime ages, since this group has an average participation rate of close to 100 percent. Therefore we would expect this group to exhibit the smallest discouraged- and addedworker elasticities.

\section{The Data}

We have used monthly seasonally adjusted labour force survey data extracted from the CANSIM Data Bank on population, number in labour force, and number employed, for ten age-sex groups covering the period January 1953 to December 1974. The age-sex groups employed were ages 14-19, 20-24, 25-44, 45-64 and 65+ for both males and females. To the extent that these groups operate in differentiated labour markets, economic theory would suggest such a taxonomy. However, we do not believe this to be necessarily the case, rather these groups are the only ones for which we can get a large number of observations of the necessary variables. It is hoped, nonetheless, that these groups do have economic meaning. The young and old, males and females, do not usually compete for the same jobs and their opportunities for using non-market time are usually quite different. 6

\section{The Statistical Estimation Procedure}

Since $P R_{t}$ and $E R_{t}$ in equation (2) refer to the same sample group in a given month and there are likely to be erroneous responses to the monthly labour force survey, the observed values of these variables are likely to have measurement errors which will produce a correlation between $E_{t}$ and $\varepsilon$. As a result, ordinary least squares estimates of $b$ (and quite possibly the other coefficients) will be biased. ${ }^{7}$ This type of bias can be reduced by using an instrumental variable for $\mathrm{ER}_{t} \cdot$ Using an instrument will also produce 
consistent estimates, which in view of the large size of our sample (264 observations) is a desirable property.

$E R_{t-3}$ is used as the instrument for $E R_{t}$. It seems to satisfy the requirements for a good instrument. Since individuals stay in the labour force survey sample for six months, a sixth of the sample population being replaced each month, there is likely to be a correlation between the measurement errors in ER (and PR) obtained from consecutive surveys. This serial correlation in errors should be considerably reduced by lagging ER by three months, since it implies that half of the sample population will have been replaced. On the other hand, such a lag is short enough so that there will still be a high positive correlation between the true values of $\mathrm{ER}_{t}$ and $\mathrm{ER}_{t-3^{*}}$

This problem of measurement bias is less likely to arise with respect to $O E R_{t}$, since $P R_{t}$ and $O E R_{t}$ refer to different population groups and $O E R_{t}$ is an aggregate of the $\mathrm{ER}_{t}$ 's in nine other groups. Therefore, OER $\mathrm{t}_{\mathrm{t}}$ is used as the instrument for itself, as are $T$ and $T^{2}$.

Initial attempts to estimate equation (2) using an ordinary-leastsquares instrumental variables technique produced Durbin-Watson statistics which indicated significant first order autocorrelation. To overcome this problem we have utilized a Cochrane-Orcutt iterative instrumental variables technique.

\section{Empirical Results and Their Interpretation}

6.1 The Existence of Added- and Discouraged-Worker Effects

The results of the estimation of equation (2) for the ten sex-age groups are presented in Table 1. The coefficients of the discouraged variable, $E R_{t}$, are positive (as hypothesized) for all ten groups. Except for one group, the coefficients are significant at least at the $90 \% 1$ evel. The coefficients 


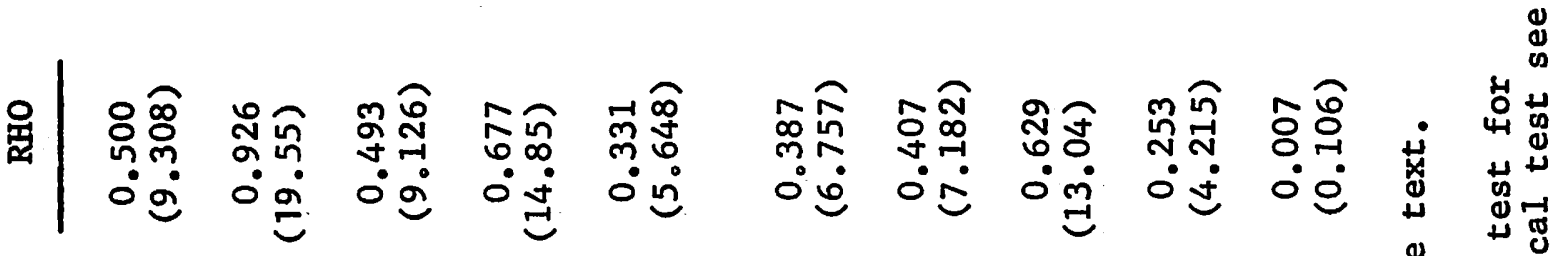

雍

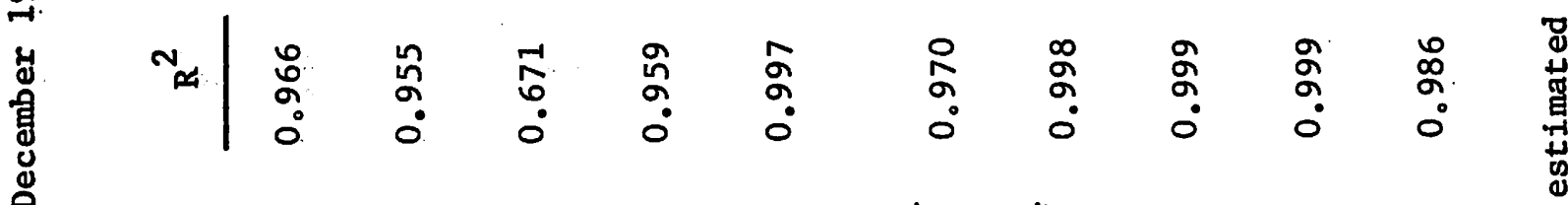

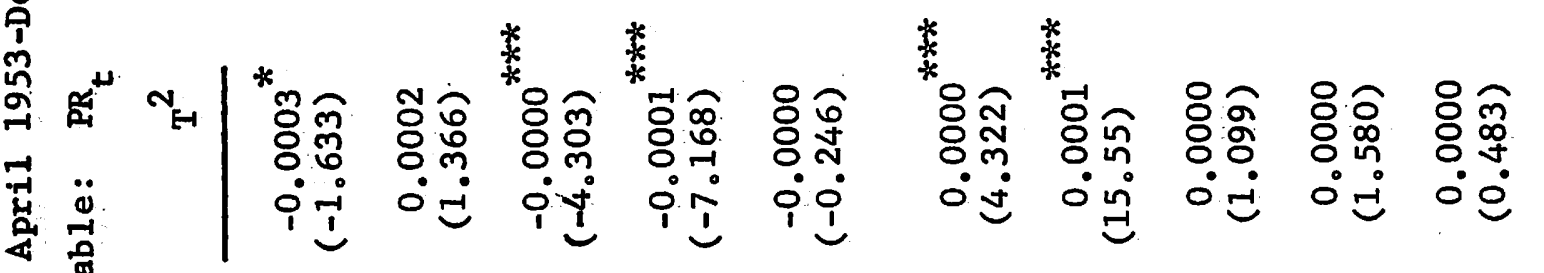

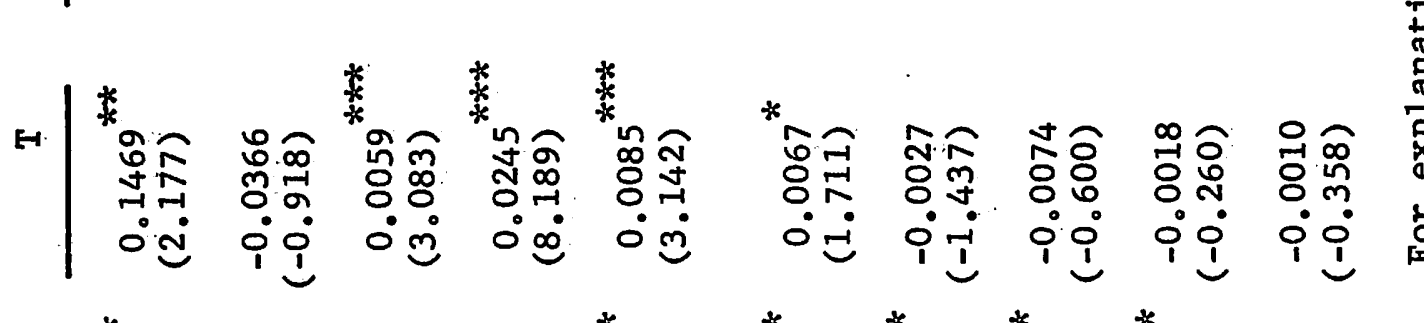

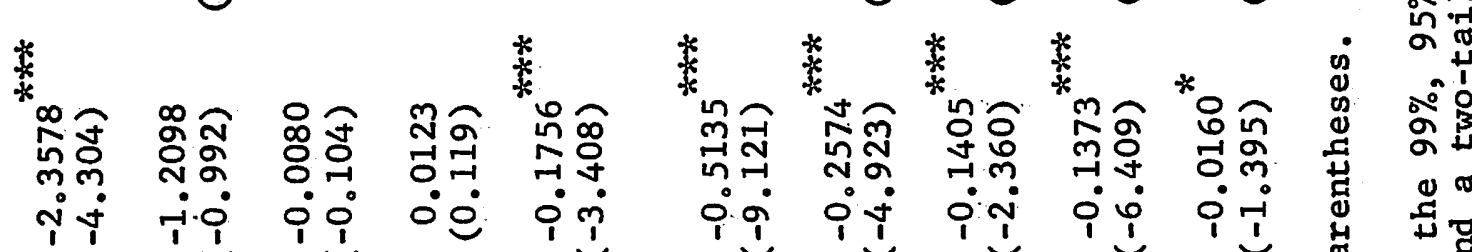

资|

莳

䑻.

กิ ${ }^{*}{ }^{*}$ 娄

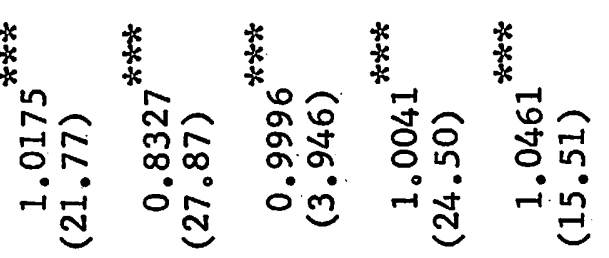

我

त品

मे

겅

点 岁

岕.

\& $E$

in

क्षिए

不

ㅇำ

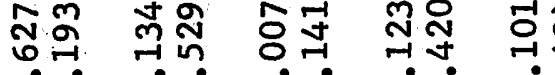

-i்

雚.

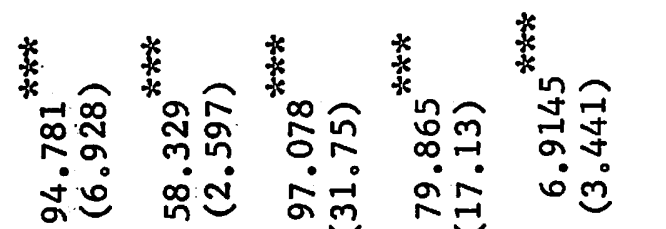

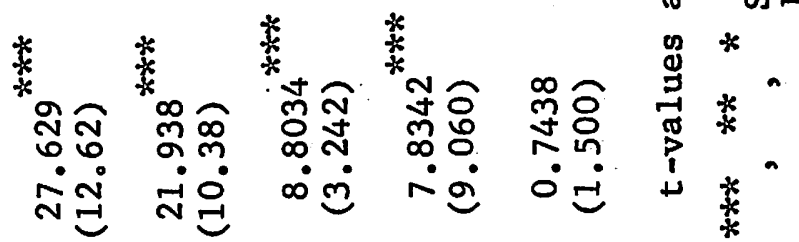

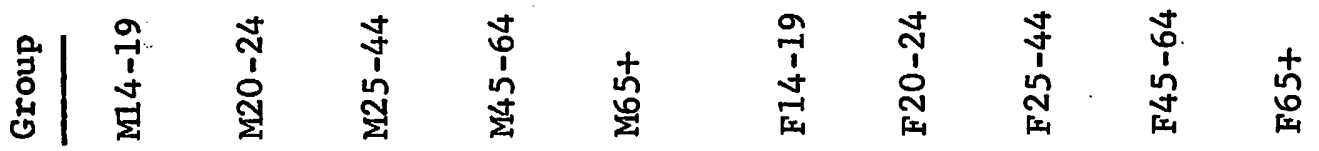


of the added-worker variable, $\mathrm{OER}_{t}$, are negative (as hypothesized) for nine out of the ten groups, and are significant at least at the $90 \%$ level for seven of the groups. These results provide strong evidence for the simultaneous existence of distinct discouraged- and added-worker effects for most of the sex-age groups in Canada during the period 1953-1974.

The cases where the two effects are found to be insignificantly different from zero appear explainable in the context of the primarysecondary labour force taxonomy. Groups with a high degree of labour force attachment are expected to exhibit sma11 discouraged-and added-worker effects, in which case the magnitudes of the corresponding coefficients are quite likely to be insignificantly different from zero. Therefore, it is not altogether surprising that the discouraged-and added-worker effects in Table 1 for males 25-44 are both insignificant. This group had a mean participation rate of 97.4 percent over the sample period and is traditionally considered part of the primary labour force. Therefore, we would expect it to reveal very little, if any, sensitivity to changes in labour market conditions.

The added-worker effect is also found to be insignificantly different from zero at standard levels of significance for males 20-24 and 45-64. For much of the period under investigation these two groups appear to have shared with the males 25-44 the characteristic of a high degree of labour market attachment. Their mean participation rates over the whole period were 88.2 and 91.3 per cent, respectively. Therefore, the absence of added-worker effects for these two groups is not too surprising. But one might wonder why these groups revealed significant discouraged-worker effects, whereas males 25-44 did not. Apparently, the answer lies in the differing economic opportunities and realitias facing these groups. 
When jobs become scarce males 20-24 may decide to continue their formal education so that their earning potential will be higher when labour market conditions improve, rather than search for employment with a low probability of success. Presumably they are able to do this because they receive financial support from their (working) parents, bursaries or subsidized loans. When males 45-64 lose their jobs it is usually exceedingly difficult for them to find new ones. Their planned retirement may not be far off. In addition, they are likely to have accumulated wealth that they can live on, have (working) children who can support them, or be entitled to receive some payments from (public or private) pension plans.

Males aged 25-44 are in an entirely different situation. They are less likely to have accumulated enough wealth or pension rights, and to have (working) children or parents who can support them. On the other hand, their financial needs are likely to be higher--larger outstanding debts and a larger number of dependents. Even if they are unemployed they usually stand a better chance of finding a job than other members of their family. Since their expected remaining working life is shorter than for males 20-24, the expected return from continuing their education is smaller than for the younger males. Moreover, since they have been out of school for a longer period of time, the resumption of formal schooling will be more difficult for them.

6.2 Tine Magnitudes of the Effects Across Groups

One can compare the magnitudes of the discouraged-and added-worker effects across different groups by looking at the partial elasticities of PR with respect to ER and OER, measured at the variables' means. The discouragement elasticities, $\bar{\eta}_{\mathrm{PR}, E R}$, appear in column 2 and the absolute value of the added-worker elasticities, $\left|\bar{\eta}_{\mathrm{PR}, \mathrm{OER}}\right|$, appear in column 3, of Table 2 . 
Table 2

Estimated Partial Elasticities ${ }^{a}$

(at the variables means)

M 14-19

M 20-24

M 25-44

M 45-64

M 65+

F 14-19

F 20-24

F 25-44

F $45-64$

F $65+$
$\overline{\mathrm{PR}}$

(1)<smiles>[R17][R17]#C</smiles>

(2)

$42.5 \%$

88.2

97.4

91.3

27.0

32.1

52.9

32.6

29.7

5.2

1.420

1.034

0.007

0.117

1.051
$\left|\bar{\eta}_{\mathrm{PR}, \mathrm{OER}}\right|$

(3)

2.947

0.690

0.003

$0.00^{b}$

0.346

0.859

0.252

0.244

0.255

0.169

${ }^{a}$ Calculated from the coefficients of Table 1.

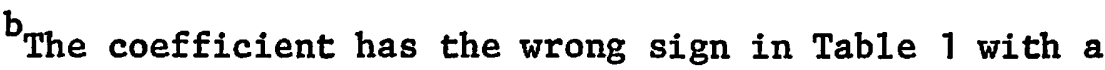
calculated elasticity of 0.006 . We, therefore, assign a zero value. 
It can be seen that for each sex-age group, with the exception of the males 14-19, $\bar{\eta}_{\mathrm{PR}, \mathrm{ER}}>\left|\bar{\eta}_{\mathrm{PR}, \mathrm{OER}}\right|$. While the proposition that people should be more sensitive to changes in their own demand conditions than in those facing others may have some intuitive appeal, we are not aware of any theoretical argument that would satisfactorily explain this result.

In view of the discussion in Section 3 concerning the primary and secondary labour forces we anticipated the finding that both $\bar{\eta}_{\mathrm{PR}, \mathrm{ER}}$ and $\left|\bar{\eta}_{\mathrm{PR}, \mathrm{OER}}\right|$ are smaller for males 25-44 and 45-64 than for all other groups, and focusing on males alone, that the magnitudes of the absolute values of both elasticities form a U-shaped pattern with respect to age.

As concerns the female groups, it may be the case that females 20-24 should be considered part of the primary labour force. Large numbers of females in this age "group are either single (one-person families) or married without children, but with a husband attending school. These women are the sole, or main, income earner for their family unit, and as such, are likely to have a high attachment to the labour market. Among the female groups, they have the highest mean participation rate, 52.9 percent (which is also higher than for males $14-19$ and $65+$ ).

The partial elasticities in columns (2) and (3) of Table 2 provide at least some support for this view. There is a U-shaped relationship between $\bar{\eta}_{\mathrm{PR}, \mathrm{ER}}$ and age for females, with a minimum at the 20-24 age group. In addition, $\left|\bar{\eta}_{\mathrm{PR}, \mathrm{OER}}\right|$ is lower for females 20-24 than for females 14-19. But contrary to what we would expect with this argument, $\left|\bar{\eta}_{\mathrm{PR}, \mathrm{OER}}\right|$ continues to decline as we move to higher age groups.

Comparing the magnitudes of these elasticities for males and females of the same age, reveals that both partial elasticities are higher for females 25-44 and 45-64, and for males 20-24. This is, of course, consistent with our 
discussion above concerning the primary labour force groups. It is interesting to note that both elasticities are larger for males than females in the 14-19 age group. This is probably associated with a higher return to schooling for males than for females. Mean earnings for males are significantly higher than for females in this age group. ${ }^{9}$ Thus, job loss and zero earnings will imply a larger reduction in the opportunity cost of schooling and, hence, a higher return to schooling for the males than the females. 10

\subsection{Comparisons with Other Studies and Other Formulations}

Since the arguments outlined above are based on economic theory one would expect them to hold for other countries besides Canada. It is, therefore, reasurring to find that Dernburg and Strand $(1966,77)$ reported results similar to ours for the U.S. They found significant discouraged- and added-worker effects for most sex-age groups forming a pattern similar to the one we found for Canada. They also only found both the discouragedand added-worker effects to be insignificant for males 25-34 and males 35-44. For males 20-24 they also found a significant discouraged-worker effect and an insignificant added-worker effect, as we did. The main inconsistency between our results and theirs is that they found a significant added-worker effect for males 45-54 and 55-64, whereas we did not. As was already mentioned, the other attempt to isolate the two effects, Barth (1968), in general failed to find significant added-worker effects.

In order to determine whether our results depend on the specific formulation of equation (2) we tried two other time trend specifications-one linear in $\mathrm{T}$ and another, a polynomial of the third degree in $\mathrm{T}$--as well as a double-log formulation in $P R, E R$ and $O E R$, but semi-log in $T$. For brevity we do not present the results; they can be obtained upon request. All formulations yield positive effects for ER and negative ones for OER, 
and the constant elasticities of the double-log formulation are very similar to those reported in Table 2. The most interesting difference between the results of Table 1 and those of the double-log formulation is the finding of significant added-worker effects for males 25-44 and 45-64. A similar result was obtained with the linear time trend formulation.

\section{Net Cyclical Response}

Abstracting from secular and seasonal factors, the net effect of a cyclical change in aggregate demand on a group's labour force participation

rate, $\frac{\partial P R}{\partial D}$, can be decomposed as follows

(3) $\quad \frac{\partial P R}{\partial D}=\frac{\partial P R}{\partial E R} \frac{\partial E R}{\partial D}+\frac{\partial P R}{\partial O E R} \frac{\partial O E R}{\partial D}$.

$\frac{\partial P R}{\partial E R}$ and $\frac{\partial P R}{\partial O E R}$ represent the discouraged-and added-worker effects, respectively. Our previous discussion suggests that their magnitudes depend on the non-market opportunities of the relevant groups, as well as family preferences concerning the allocation of goods and time within the family unit. Hence, they will be different with different technologies of production in the home (consumption), preferences concerning the allocation of time, net returns to schooling, and availability of non-labour income--welfare and unemployment programs, etc. The magnitudes of $\frac{\partial E R}{\partial D}$ and $\frac{\partial O E R}{\partial D}$ depend on how a given cyclical change in aggregate demand is translated into changes in the demand conditions facing the relevant group. Clearly this depends on the extent that different sex-age groups are substitutes for each other. ${ }^{11}$. This, in turn, depends on the technology of production in each industry, the industrial mix of the economy, the training attainment (and its quality) of the various population groups, employers' preferences, legislation concerning discrimination and minimum wages, as well as on the composition of the change in aggregate demand with respect 
to changes in the demand for the output of each industry. Within this framework there is no reason to expect identical net cyclical effects on participation rates for different countries (or regions), different time periods or different sex-age groups.

Equation (3) can be used as a basis for estimating the net cyclical effects for the ten Canadian sex-age groups under investigation. Postmultiplying both sides by $\partial D / \partial t$, where $t$ denotes time, implies that time-series data can be used to estimate the net cyclical responses, provided that secular and seasonal effects are controlled for, when quantifying the four right-handside components.

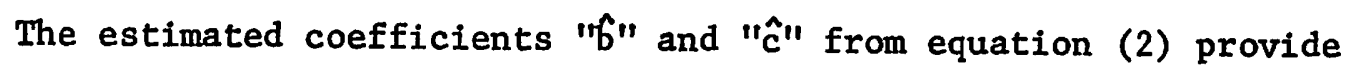
estimates of $\partial \mathrm{PR} / \partial \mathrm{ER}$ and $\partial \mathrm{PR} / \partial \mathrm{OER}$ fulfilling this requirement. The time trend variables control for secular effects, while the use of seasonally-adjusted data controls for seasonal effects. With respect to $\frac{\partial E R}{\partial D} \frac{\partial D}{\partial t}$ and $\frac{\partial O E R}{\partial D} \frac{\partial D}{\partial t}$ this requirement is satisfied by obtaining estimates of month to month changes in the detrended values of ER and OER, $\frac{d E R *}{d t}$ and $\frac{d O E R *}{s t}$, respectively. 12

The changes in detrended, seasonally adjusted, ER and OER serve as proxies for cyclical changes in own- and other-group labour demand conditions. Thus, if we can identify the periods of expansion and contraction in economic activity we can obtain a single value characterizing a group's net response to cyclical expansions, and another, its response to cyclical contractions, by estimating a mean net cyclical response of the $i^{\text {th }}$ group, $\overline{\mathrm{NCR}}_{i}$,

$$
\widehat{N C R}_{i}=\hat{b}_{i}\left(\frac{d E R^{*}}{d t}\right)_{i}+\hat{c}_{i}\left(\frac{\overline{\mathrm{dOER}^{*}}}{\mathrm{dt}}\right)_{i}
$$

once for expansionary periods and again for contractionary periods.

In view of the absence of an official reference cycle for Canada we used turning points in the Royal Bank's Coincident Index of business activity ${ }^{13}$ to identify periods of expansion and contraction. The mean net cyclical 
responses for each group calculated using equation (4) for expansionary periods and the contractionary periods appear in columns 1 and 2 of Table 3 . They indicate a net pro-cyclical (discouragement) effect for all of the male groups, except males 14-19, and for females 25-44 and 65+. No definite conclusion can be reached concerning the other four groups--males 14-19, females 14-19, 20-24 and 45-64, since a net pro-cyclical (discouragement) effect is found for one phase of the cycles and a net counter-cyclical (added-worker) effect is found for the other phase.

In columns (3)-(6) of Table 3 we compare the mean official unemployment rates for expansion and contraction periods with the corresponding unemployment rate "corrected" for the net cyclical responses. The "corrected" unemployment rate for the periods of expansion is the one which would have prevailed if expansion had not attracted people to the labour market, and for periods of contraction the rate which would have prevailed if people had not been repelled from the labour market. The comparison suggests that the net cyclical effect has only a small impact on the unemployment rate statistics. 14

Comparing only columns (3) and (5) reveals that for all the groups, except females 65+, the mean official unemployment rate is lower for the contraction periods than for the expansion ones. This finding is consistent with a pro-cyclical participation behavior, and provides support for our estimates of mean net cyclical responses and the conclusion we have drawn from them.

The finding of net discouragement for most of the groups, with hardly any evidence of net added-worker effect for any group, is at odds with the findings of the other Canadian time-series studies. They all found net added effects for at least some of the groups. It does, however, agree with the cross-sectional results for Canada (Swidinsky $(1970,1973)$, as well as with both the time-series and cross-sectional results for the U.S. 


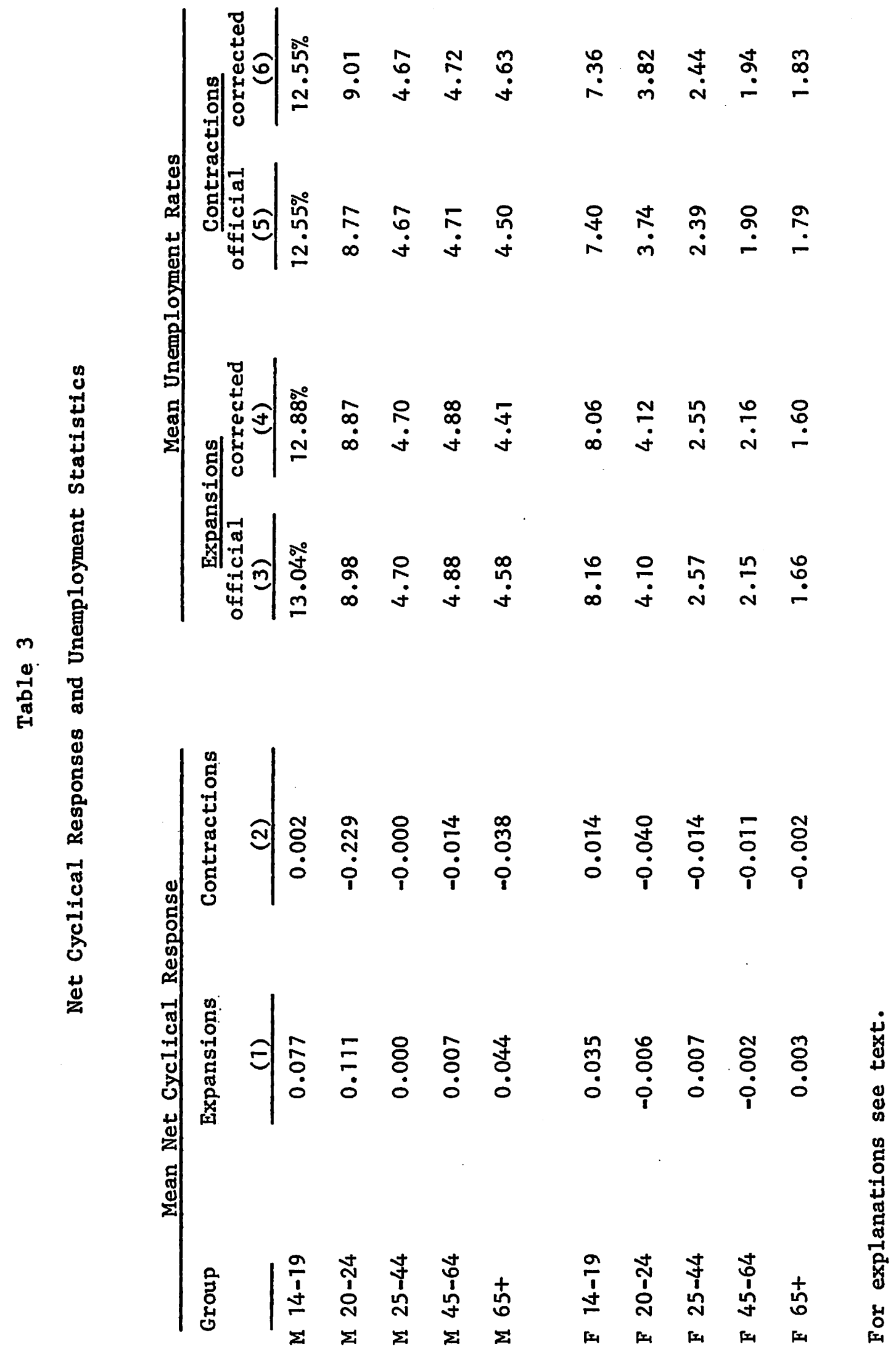


. It should be noted that these results were obtained using an entirely different method of calculating each group's net response. Their accuracy depends heavily on the assumptions that the time trends were all second degree polynomials and that $\partial \mathrm{PR} / \partial \mathrm{ER}$ and $\partial \mathrm{PR} / \partial \mathrm{OER}$ were constant over the entire period. 15

\section{A Digression on Symmetry}

The finding of opposing net cyclical effects for several of the groups (in Table 3) raises the question of symmetry in the discouraged- and addedworker effects and in the changes in demand for the services of the various groups over the cycle. Time and space limitations constrain us to deal with only the former issue.

If the discouraged- and added-worker effects merely reflect conventional substitution and income effects within the family utility maximization model, we would expect them to be symmetrical with respect to deteriorating and improving labour market conditions. But a variety of phenomena, that can be attributed to market imperfections may make these effects asymmetrical.

It has been already suggested in the literature, with support of some empirical evidence, that diplomas obtained at various stages of the educational system serve as a certification of ability for potential employers. ${ }^{16}$ The result could be, that if due to a given deterioration of labour market conditions (young) people withdraw from the labour market or defer entry into it in order to continue their studies, as market conditions improve and return to their previous levels, not all of those people will enter or re-enter the market. They may find it worth their while to wait until they earn the diploma, and derive the benefits of the certification it implies. This would suggest a larger sensitivity to deteriorating than to improving own-labour-market conditions on the part of younger people. 
The original statement of the added-worker effect (Woytinsky, 1940) was that when the breadwinner of the family lost his job, his wife or other family members would enter the labour market in an attempt to maintain the original family income. This argument seems to suggest that there is a minimum flow of expenditures that the family must "finance" via earnings. These expenditures include such items as food, shelter and long-term contractual payments. Due to imperfections in the capital market, whenever deteriorating labour market conditions reduce the family income below the (acceptable) minimum level, other family members are "forced" into the labour market. But this argument is not necessarily symetric. Improving labour market conditions that raise the breadwinner's income above the (acceptable) minimum level, will not of necessity force the other members to withdraw from the market if the desired level of family income is not bounded from above. This will produce a larger sensitivity on the part of the other family members to deteriorating than to improving labour market conditions of the breadwinner.

The last possibility we would like to mention is based on employers' seeming preference for job applicants with recent work experience. This apparent screening phenomenon may cause a group to be more sensitive to improving specific labour market conditions than to their deterioration. Suppose people are initially attracted into the labour market by increased demand, and that some of them are successful in finding jobs. If demand subsequently declines, returning to its original level, a smaller number of people are likely to leave the labour market than were initially attracted into it. This will result from the fact that individuals who entered and then lost their jobs have better employment opportunities than before, because of their work experience. 
Additional arguments could be presented but these should suffice to make a case for the possibility of non-symmetrical effects. In order to test for non-symmetry we estimated, using the procedure described in section 5 , the following equation:

$$
\begin{aligned}
\mathrm{ER}_{t}=a+b \mathrm{ER}_{t}+\operatorname{COER}_{t} & +\mathrm{dT}+\mathrm{eT} \mathrm{T}^{2}+\alpha_{1} \mathrm{D}_{1}+\alpha_{2} \mathrm{D}_{2} \\
& +\beta\left(\mathrm{D}_{1} \cdot \mathrm{ER}_{t}\right)+\gamma\left(\mathrm{D}_{2} \cdot \mathrm{OER}_{\mathrm{t}}\right)
\end{aligned}
$$

where

$$
\begin{aligned}
& D_{1}=\left\{\begin{array}{lll}
1 & \text { if } & E R_{t}-E R_{t-1}>0 \\
0 & \text { if } & E R_{t}-E R_{t-1} \leq 0
\end{array}\right. \\
& D_{2}=\left\{\begin{array}{ll}
1 & \text { if } O E R_{t}-O E R_{t-1}>0 \\
0 & \text { if OER }-O E R_{t-1} \leq 0
\end{array} .\right.
\end{aligned}
$$

For brevity we do not present these results here (they can be obtained on request). They are generally unchanged for $a, b, c, d$, and $e$, and the new coefficients $-\alpha_{1}, \alpha_{2}, \beta$ and $\gamma$ are for the most part not significantly different from zero. This implies that the implicit assumption in the literature of symmetrical effects for recession and recovery can be used as a reasonable first approximation of reality.

However, for three of the groups, the symmetry hypothesis is rejected: for males 14-19, $\alpha_{1}>0$ and $\beta<0$ (at the 90\% leve1); for males $65+, \alpha_{2}>0$ and $\gamma<0$ (at the 95\% level); and for females $65+, \alpha_{1}<0$ and $\beta>0$ (at the $99 \%$ and 95\% levels, respectively). This implies a larger sensitivity on the part of males 14-19 to a deterioration in the demand facing them than to an improvement in it, a result which is consistent with the education certification hypothesis. The males $65+$ reveal a larger sensitivity to a deterioration in the demand for other groups than to its improvement. This is consistent 
with our interpretation of the original statement of the added-worker effect in terms of a minimum required family income. The females $65+$ are found to be more sensitive to an improvement than to deterioration in their own demand conditions, a result which is consistent with the (recent) work experience hypothesis. $^{17}$ It should be noted, that these are explanations consistent with our results; we do not claim to know what the true explanations are.

\section{Concluding Remarks}

We have been successful in isolating distinct and largely symetrical discouraged- and added-worker effects as predicted by the model of joint family utility maximization. The relative magnitudes of these effects for the various sex-age groups are consistent with traditional notions of primary and secondary labour force groups--smaller for the former and larger for the 1atter.

Our discussion of the factors determining the net cyclical effect suggest that different populations with respect to time, geographic space and demographic composition are likely to exhibit different net cyclical responses. Hence the apparent differences between the net cyclical participation behavior of the Canadian and United States populations and the difference between the results obtained for Canada from time-series and cross-section studies are not too surprising. Nonetheless, our finding that Canadians, for the most part, have exhibited net discouragement agrees with the results of studies for the United States as well as with Canadian studies using cross section data. Contrary to the other Canadian time-series studies we found no clear evidence of net added-worker effects.

Finally, our estimates of the net cyclical effects implied that during the sample period, 1953-74, the cyclical fluctuations in each group's labour 
force participation had little if any effect on the accuracy of the official. unemployment statistics. That is, "hidden unemployment" or "exaggerated unemployment" seems to have been virtually non-existent in Canada during this period. 


\section{Footnotes}

1 Their results imply an added-worker effect of 1.4 females aged 35-44 and 1.1 aged 45-54 per exhaustion. These numbers seem unrealistic to us.

${ }^{2} \mathrm{~A}$ decline in the (expected) reward obtained from market activities has no real income effect on labour force participation. See Ben-Borath (1973, 702).

3 The relative merits of the various possible measures of labour market conditions were discussed by Mincer $(1966,78-80,84-91,109 n)$ and Bowen and Finegan (1969, 502-4, 516-22).

${ }^{4}$ Note that the basic assumption implied by this relationship is that changes in households' tastes and in their non-market rewards are not correlated with cyclical changes in demand conditions.

${ }^{5}$ See, for example, Mincer $(1966,102)$. This interpretation has been challenged recent1y by Ben-Porath (1973, 698-701). He concludes that for many people participation (or non-participation) is a "permanent" situation. This implies that the various groups differ in their proportion of permanent participants to non-participants.

6 The use of less than perfect data is likely to reduce rather than increase the chances that the hypotheses implied by the theory will be substantiated.

7See, for example, Mincer (1966, 89-91) and Proulx (1969, 272).

8 Due to the use of instrumental variables and the Cochrane-Orcutt iterative techniques the t-statistics no longer have a student-distribution. They retain, however, the property of having an asymptotic normal distribution. Nonetheless, in order to obtain a conservative statistical test, that is, one which reduces the possibility type I errors, we shall use the critical values of the student-distribution with $200 \mathrm{~d} . \mathrm{f}$.

${ }^{9}$ See, for example, Podoluk (1968, 60 and 64-5).

10 The discussion in this sub-section could be summarized by the hypothesis of a negative relationship between the sensitivity of a group's participation to labour market conditions and the degree to which it has "primary' labour force" characteristics. The latter will be measured by the group's mean participation rate, $\overline{\mathrm{PR}}$. Using the ten sex-age groups we can estimate

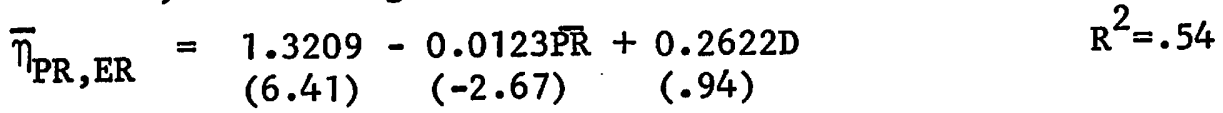

$$
\begin{aligned}
& \left|\bar{\eta}_{\mathrm{PR}, \mathrm{OER}}\right|=\underset{(-0.87)}{-0.6810}+\underset{(2.22)}{0.0982 \overline{\mathrm{PR}}}-\underset{(-2.41)}{0.0017}(\overline{\mathrm{PR}})^{2}-\underset{(-1.15)}{2.3234 \mathrm{D}}+\underset{(1.77)}{0.0937 \mathrm{SD}} \\
& \mathrm{R}^{2}=.68
\end{aligned}
$$


where $D=1$ for males and 0 for females, $\mathrm{SD}=\overline{\mathrm{PR}} \cdot \mathrm{D}$, and $t$-values are given in parentheses.

The negative relationship is found for $\bar{\Pi}_{P R}, E R$, and it is significant at the $95 \%$ level in a one-tailed test. The relationship for $\left|\bar{\eta}_{\mathrm{PR}, \mathrm{OER}}\right|$ is an inverse $U$ with a maximum for $\overline{P R}=29.1 \%$, so that for most groups the negative relationship hypothesis is substantiated. This relationship is significant at the $90 \%$ level.

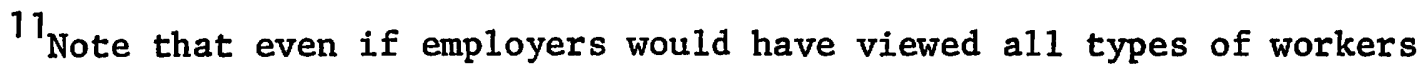
as perfect substitutes, we would not in general expect $\partial E R / \partial D=\partial O E R / \partial D$. If employers hire additional, $\Delta E$, workers we might expect that $U_{i} / \Sigma U_{i} \Delta E$ will be hired from the $i$-th group, where $U_{i}$ denotes the unemployed in the $i-t h$ group. This implies that $\partial E R_{i} / \partial D=\left(\Delta E / \Sigma U_{i}\right)\left(U_{i} / P_{i}\right)$. Then $\partial E R / \partial D=\partial O E R / \partial D$ would hold only if $U_{i} / P_{i}$ were identical for all $i$, which is clearly not the case.

12 The detrended values of the variables being

$$
x_{t}^{*}=x_{t}-\hat{k} T-\hat{i} T^{2} \text {, }
$$

where $x_{t}^{*}$ and $x_{t}$ are respectively the detrended and observed values of $\mathrm{ER}_{t}$ and OER $_{t}, \hat{k}$ and $\hat{1}$ are the estimated coefficients from multiple regressions of $\mathrm{ER}_{\mathrm{t}}$ and $\mathrm{OER}$ on $\mathrm{T}$ and $\mathrm{T}^{2}$ with an intercept, using the Cochrane-Orcutt Itêrative Têthnique.

13 We would like to thank Dr. R. W. Baguley, Senior Economist of the Royal Bank of Canada for providing us with the information about the Bank's Coincident Index of Business Activity. The index is based on real gross national product, real domestic product and male 25 and over unemployment rate series. The turning points in economic activity are identified from the quarterly deviations of the value of the index from its log-linear trend.

${ }^{14}$ This result is consistent with Swidinsky's $(1973,74)$ conclusion that the Canadian labour force tends to be much less responsive to employment conditions than the U.S. labour force.

${ }^{15}$ The assumption of constant (over time) cyclical labour force effects seems to underly all of the studies we are aware of. An attempt to test this assumption for the period 1953-74 indicated that the discouraged-worker effects were fairly constant for most groups, although they increased somewhat for females 25-44 and 65+. The added-worker effects appear to be less constant, decreasing somewhat over time for females 14-19 and 65t, and for males 20-24, 25-44 and 65t, but increasing somewhat for females $25-44$.

${ }^{16}$ See Arrow (1973), Taubman and Wales (1974, 153-159) and the estimates of private rates of return to college dropouts Hannoch (1967, 324-5).

17 The non-symmetries exhibited by both the males and females $65+$ are also consistent with an ex-post awareness of additional non-pecuniary benefits from work activity, e.g., a satisfaction from "useful" activity. 
References

Arrow, K. (1973) "Higher Education as a Filter," Journal of Public Economics, 2, no. 3, 193-216.

Barth, P. (1968) "Unemployment and Labor Force Participation," Southern Economic Journa1, XXXIV, no. 3, 375-382.

Ben-Porath, Y. (1973) "Iabor-Force Participation Rates and the Supply of Labor," Journal of Political Economy, 81, no. 3, 697-704.

Bowen, W., and Finegan, T. (1969) The Economics of Labor Force Participation (Princeton University Press, Princeton, New Jersey).

Cain, G. (1966) The Labor Force Participation of Married Women (The University of Chicago Press, Chicago).

Davis, N. (1971) Cycles and Trends in Labour Force Participation," 1953-1968, Dominion Bureau of Statistics, Special Labour Force Studies, Series B, no. 5 .

Dernberg, T. and Strand,K. (1966) "Hidden Unemployment 1953-62: A Quantitative Analysis by Age and Sex," American Economic Review, LVI, no. 1, 71-95.

Hanoch, G. (1967) "An Economic Analysis of Earnings and Schooling," Journal of Human Resources, II, no. 3, 310-29.

Mincer, Jacob (1966) "Labor Participation and Unemployment: A Review of Recent Evidence," in R. A. Gordon and M. S. Gordon, eds., Prosperity and Unemployment (John Wiley and Sons, Inc., New York) 73-112.

Officer, L. and Andersen,P. (1969) "Labour-Force Participation in Canada," Canadian Journal of Economics, II, no. 2, 278-87.

Podoluk, J. (1968) Incomes of Canadians (Dominion Bureau of Statistics, Ottawa).

Proulx, P. (1969) "La variabilité cyclique des taux de participation à la main-d'oeuvre au Canada," Canadian Journal of Economics, II, no. 2, 268-77.

Strand, K. and Dernberg,T. (1964) "Cyclical Variation in Civilian Labor Force Participation," Review of Economics and Statistics, 46, no. 4, 378-91.

Swan, N. (1974) "The Response of Labour Supply to Demand in Canadian Regions," Canadian Journal of Economics, VII, no. 3, 418-33.

Swidinsky, R. (1970) "A Note on Labour Force Participation and Unemployment," Canadian Journal of Economics, III, no. 1, 147-50.

(1973) "Unemployment and Labour Force Participation," Industrial Relations, (Lava1) 28, no. 1, 56-75. 
Taubman, P., and Wales,T. (1974) Higher Education and Earnings: College as an Investment and a Screening Device (McGraw-Hill Book Company, New York).

Tella, A. (1964). "The Relation of Labor Force to Employment," Industrial and Labor Relations Review, 17, no. 3, 454-69.

(1965) "Labor Force Sensitivity to Employment by Age, Sex," Industrial Relations, 4, no. 1, 69-83.

Woytinsky, W. (1940) Additional Workers and Volume of Unemployment in the Depression (Social Science Research Council, Washington, D.C.). 